\title{
Effect of moisture content, forming temperature and structural components on Biocoke solidification from various biomass resources
}

\author{
Nami TAGAMI $*$ and Tamio IDA* \\ *Bio-Coke Research Institute, Kindai University \\ 3-4-1 Kowakae, Higashiosaka, Osaka 577-8502, Japan \\ E-mail: nami_t@kindai.ac.jp
}

Received: 17 January 2018; Revised: 25 June 2018; Accepted: 18 September 2018

\begin{abstract}
Biocoke (BIC) is a solid fuel made from various types of biomass resources. BIC is expected to be a coal substitute fuel because of its high density and high hardness characteristics. In a previous study, we have indicated the effects of formation conditions on BIC properties. In this study, the main structural components of biomass: cellulose, hemicellulose, and lignin, were investigated to systematically deduce the forming properties from the biomass components. The initial moisture content is a critical parameter due to the solid surface reactions by lignin in the formation of BIC. The initial moisture content affects the thermal softening temperature of hemicellulose and lignin as an adhesive of BIC. Thus, we investigate the effects of biomass components and the initial moisture content on compressive strength of BIC. The raw materials of this study were woody biomass (trunk from conifer trees and bark from conifer trees) and herby biomass (bagasse and rice straw). The result of compressive strength shows that trunk BIC has the highest compressive strength among BIC made from those biomass materials. The maximum compressive strength has a directly proportional relation to cellulose content. Due to the increase of the initial moisture content, the maximum compressive strength decreased. The maximum strength could be approximated by a quadratic curve for hemicellulose content.
\end{abstract}

Keywords : Biomass, Biocoke, Biomass components, Moisture content, Compressive strength

\section{Introduction}

Biocoke (BIC) is a solid fuel made from various types of biomass recourses (Honjo, 2008, Mizuno et al., 2012). BIC has high physical and mechanical characteristics as follows: high apparent density; close to $1.4-1.5 \mathrm{~g} / \mathrm{cm}^{3}$, high compressive strength; 40-120 MPa (Mizuno et al., 2012). The high apparent density characteristic results in slow combustion because of the low air diffusion into the core of the BIC (Ito et al., 2012, Fuchihata et al., 2013). The high compressive strength characteristic leads to the solid fuel maintaining its shape in a blast furnace and a shaft type furnace (a cupola furnace) (Ishii et al., 2009). Previous experimental studies clarified what kinds of biomass and forming conditions (especially, forming temperature and initial moisture content) have significant effects on the compressive strength of BIC (Mizuno et al., 2011, 2015).

The softening behavior of hemicellulose and lignin affects the mechanism to solidify BIC. Biomass particle consolidates by the pressurization and lignin combines by chemical condensation bonding (networking by the dehydration condensation reaction of the lignin) (Goto et al., 2012). The softening temperature of dried hemicellulose and lignin is $423 \mathrm{~K}, 473 \mathrm{~K}$ each. However, when the moisture content is high, the softening temperature becomes lower (333K, 373K in moisture content approximately 20\%) (Furuta, 2005). The thermal softening temperature of each biomass are different because the ratio of ingredient constituting biomass varies. In general, woody biomass has 40-50\% cellulose, $15-35 \%$ hemicellulose and 18-35\% lignin, however, each part of the trees provide different components (Idei, 1993). On the other hand, there are few documents which showed components rate of herby biomass. For example, rice straw has 35\% cellulose, 22\% hemicellulose and 13\% lignin (Klason lignin) (Rabemanolontsoa and Saka, 2012). It shows that all of biomass have different adhesion effects due to the different components. Also, the 
forming conditions of BIC which causes compressive strength differs according to the kinds of biomass. The main objective of this study is to clarify the effects of biomass components (cellulose, hemicellulose, and lignin) and the initial moisture content and the forming temperature on compressive strength of BIC.

\section{Equipment and procedure}

\subsection{Experimental materials}

Trunk from conifer trees, bark from conifer trees, bagasse and, rice straw, were selected as the experimental materials. Raw materials were crushed by a cutter crusher and classified in particle sizes 150-300 $\mu \mathrm{m}$ with a sieve shaker (Fig. 1). Raw materials were analyzed to obtain a percentage of the chemical components with components analysis of wood (JWRS, 1985, 2000). The following are the details.

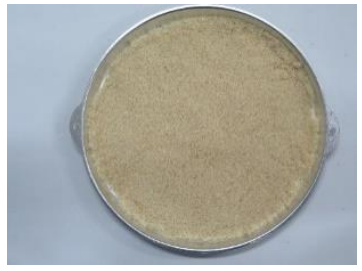

(a) Trunk of conifers

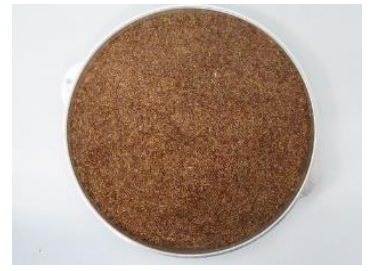

(b) Bark of conifers

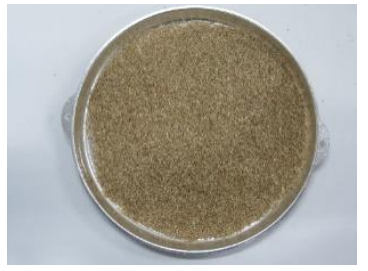

(c) Bagasse

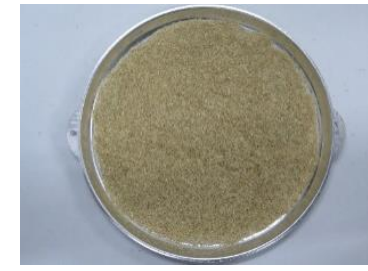

(d) Rice straw

Fig. 1 Experimental materials.

\subsection{Quantitative determination of cellulose, hemicellulose, and lignin}

A soxhlet extraction removes an organic solvent soluble substance such as oil in raw materials with a benzene and ethanol mixture (volumetric ratio is 2:1). After the oil extraction process, samples were dried in an oven.

By using a sulfuric acid method, the sample was carbohydrates hydrolyzed, and assay lignin was made into a residue. At first $72 \%$ of sulfuric acid was added to the degreased samples. Polysaccharide components in samples swelled with $72 \%$ sulfuric acid and dissolved. Next, the degreased samples were diluted. Thus the acid became $3 \%$. After that, the samples were boiled and hydrolyzed. Lignin that was provided in this way is Klason lignin.

Chlorous acid sodium and acetic acid were added to degrease samples for oxidation decomposition. Then, solubilize lignin, and polysaccharides ingredients were separated as residual substances. The residual substance was holocellulose consist of cellulose and hemicellulose. Furthermore, holocellulose was soaked with $17.5 \%$ sodium hydroxide solution, and a dissolving ingredient was removed. As a residual substance, $\alpha$ cellulose was provided. The amount of $\alpha$ cellulose was defined as cellulose. The hemicellulose was immersed into $17.5 \%$ sodium hydroxide solution and dissolved. The value that subtracted the amount of $\alpha$ cellulose from the amount of holocellulose was defined as the amount of hemicellulose. Table 1 shows the result of the quantitative determination of each component.

Table 1 Component of samples (dry wt \%).

\begin{tabular}{ccccc}
\hline Raw materials & Trunk of conifers & Bark of conifers & Bagasse & Rice straw \\
\hline Cellulose & 47.8 & 26.2 & 40.2 & 26.0 \\
\hline Hemicellulose & 28.4 & 8.9 & 20.9 & 35.1 \\
\hline Lignin & 29.7 & 49.0 & 16.3 & 13.2 \\
\hline Others & - & 15.9 & 22.6 & 25.7 \\
\hline
\end{tabular}

\subsection{Forming BIC and compressive strength test of BIC}

Fig. 2 shows a schematic drawing of a batch type formation device of BIC. Fig. 3 shows a schematic of the BIC forming process. Table 2 shows conditions of forming BIC. These conditions are under a subcritical water condition. At first, the initial moisture content of raw materials was adjusted for each forming condition $(5 \mathrm{wt} \%$, 7wt $\%$, 10wt $\%$, $12 \mathrm{wt} \%$, and $15 \mathrm{wt} \%)$. The material was put into a cylinder and sealed with spacers. A silicon rubber prevents the release 
of heat. The material is pressed in $21.7 \mathrm{MPa}$ by a hydraulic press and heated by an electric furnace up until the preset temperature. After reaching the preset temperature, the temperature was kept for $3.75 \mathrm{~min}$. After cooling down to $298 \mathrm{~K}$ by a cooling fan, BIC was removed.

The compressive strength of each BIC sample was measured by a compression testing machine (SHIMADU, UH- F2000KNA). The BIC sample was applied from the top of BIC at a loading rate of $1.5 \mathrm{~mm} / \mathrm{min}$. one by one. The compressive strength was defined as the maximum nominal stress from a stress-strain diagram.

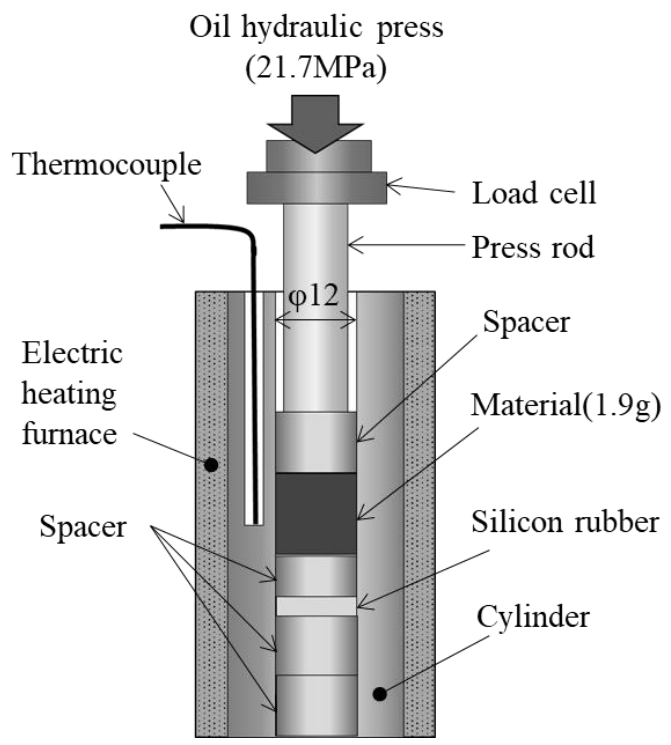

Fig. 2 Schematic drawing of BIC forming device.

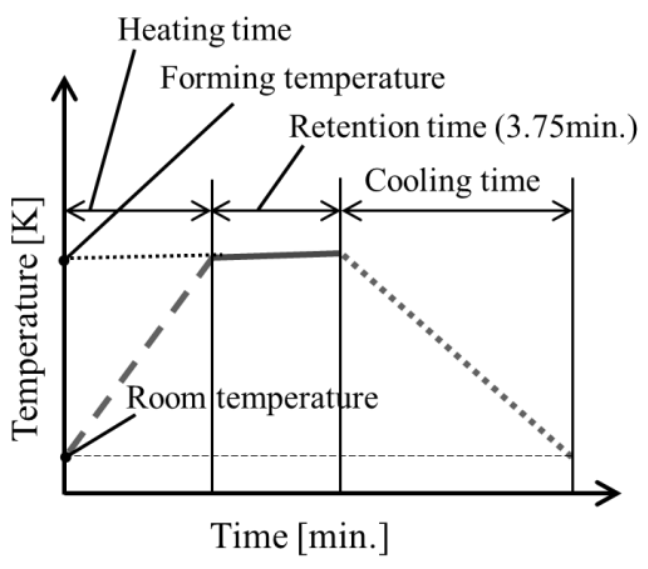

Fig. 3 Schematic of BIC forming process.

Table 2 Conditions of forming BIC.

\begin{tabular}{cc}
\hline Raw materials & $\begin{array}{c}\text { Trunk of conifers, Bark of conifers, } \\
\text { Bagasse, and Rice straw }\end{array}$ \\
\hline Particle size $[\mu \mathrm{m}]$ & $150-300$ \\
\hline Initial moisture content $[\mathrm{wt} \%]$ & $5,7,10,12,15$ \\
\hline Quantity $[\mathrm{g}]$ & 1.9 \\
\hline Loading pressure $[\mathrm{MPa}]$ & 21.7 \\
\hline Forming temperature $[\mathrm{K}]$ & $393-473$ (every 20K) \\
\hline Retention time [min.] & 3.75 \\
\hline
\end{tabular}

\section{Results and discussion}

\subsection{BIC properties}

Fig. 4 shows appearance of BIC samples. BIC which formed at high initial moisture content and high temperature become umber or black. Bark including a lot of lignin becomes black at low temperature (413K) and low initial moisture content $(5 \mathrm{wt} \%)$. Rice straw BIC at $473 \mathrm{~K}$ with $15 \mathrm{wt} \%$ initial moisture content has cracks, and all samples could not be formed at high temperature $(473 \mathrm{~K})$ with high initial moisture content. In the BIC forming process, moisture might cause the increase of internal pressure, and it may cause damage to the device because of pressure overload when internal pressure reaches $43 \mathrm{MPa}$. Thus, it is an unsuitable forming condition of BIC.

Fig. 5 shows apparent density of BIC formed from each sample for the forming temperature and the initial moisture content. For $5 \mathrm{wt} \%$ initial moisture content, as the forming temperature becomes higher, the apparent density increases. In case of the initial moisture content $7 \mathrm{wt} \%$, the increase of forming temperature rises the apparent density, as with $5 \mathrm{wt} \%$. However, the apparent density reaches the maximum value at the particular temperature and decreases afterwards. The effect on the apparent density for the forming temperature is small at the temperature range of $413-473 \mathrm{~K}$ and the initial moisture range of $10-15 \mathrm{wt} \%$. BIC with the initial moisture content above $10 \mathrm{wt} \%$ has the high 
apparent density (1.33-1.45 $\left.\mathrm{g} / \mathrm{cm}^{3}\right)$ regardless of the forming temperature. Raw material are heated and compressed simultaneously during the BIC forming process. It is known that hemicellulose present in biomass is hydrolyzed by heating, then softening and fluidity are improved. The softened hemicellulose fills voids between particles and sub-critical water destroys the micro organizational structure and the micro pore structure. Thus, the volume reduces. These make high apparent density possible. Fig. 5 indicates that the apparent density increases at high forming temperature when the initial moisture content is low. The apparent density is approximately constant regardless of the forming temperature when the initial moisture content is high. This result shows the hydrolysis reaction conditions of hemicellulose when forming temperature and initial moisture content are changed under constant-pressure condition. We found that hemicellulose does not hydrolyze under low initial moisture content and

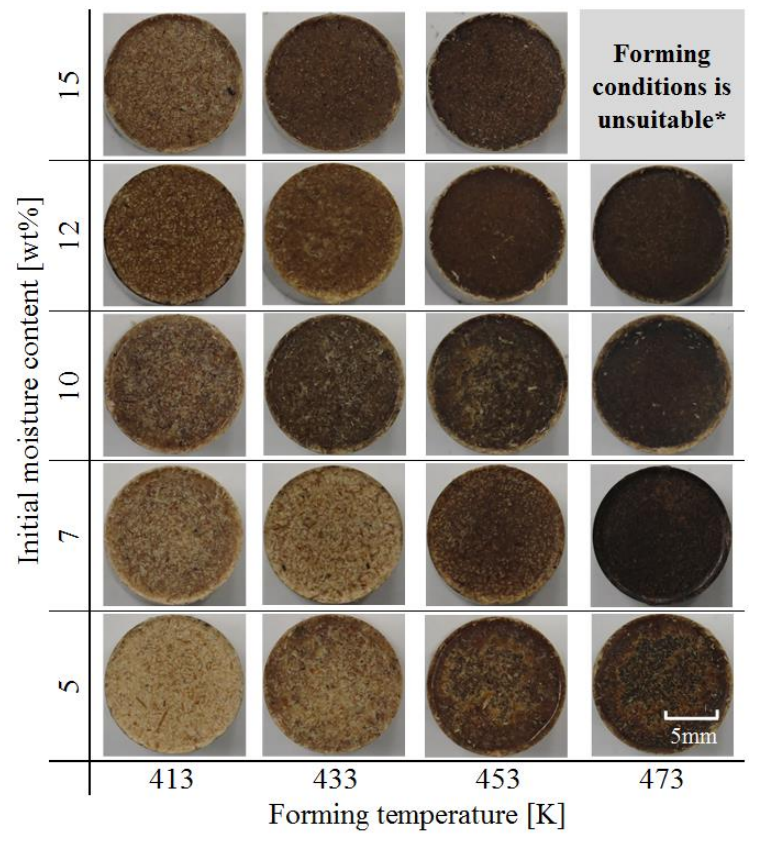

(a) Trunk of conifers

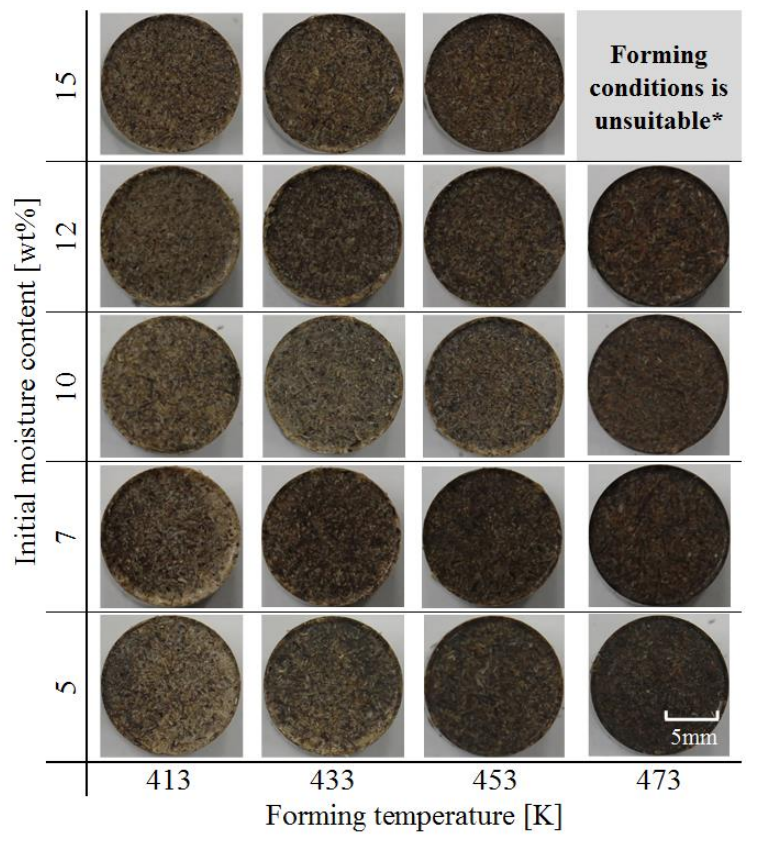

(c) Bagasse

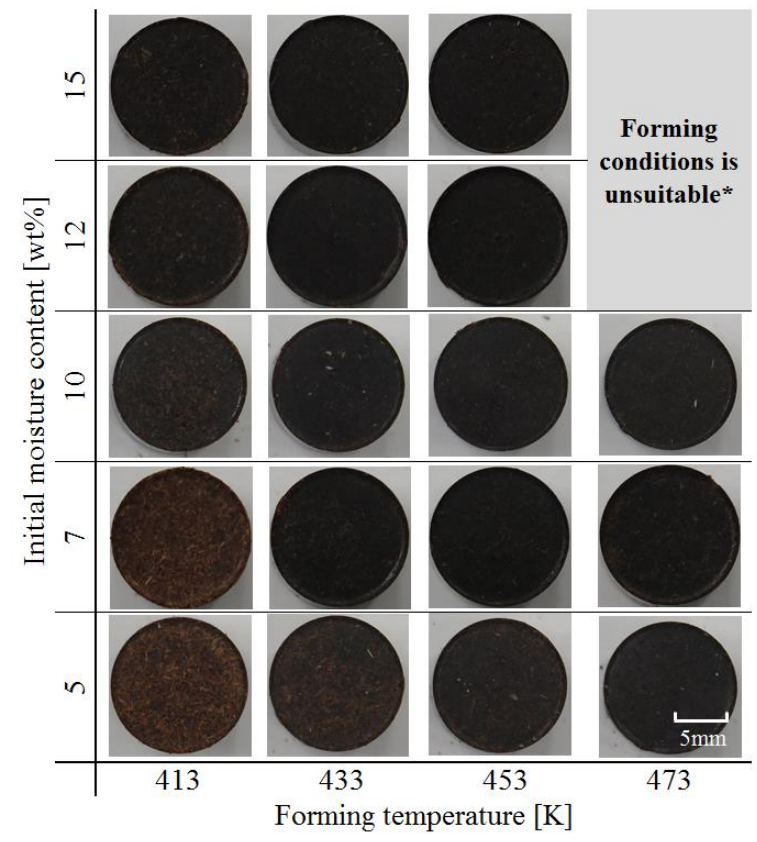

(b) Bark of conifers

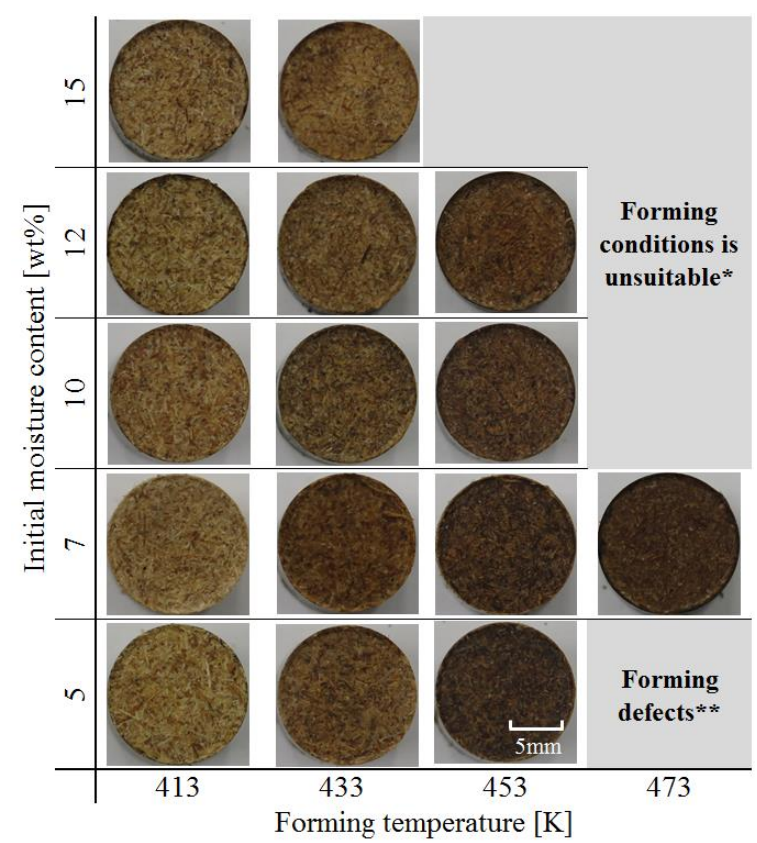

(d) Rice straw

Fig. 4 Appearance of BIC samples from different forming conditions:

*; A rise in pressure of the inside at the time of the forming. **; Forming defects due to crack initiation. 


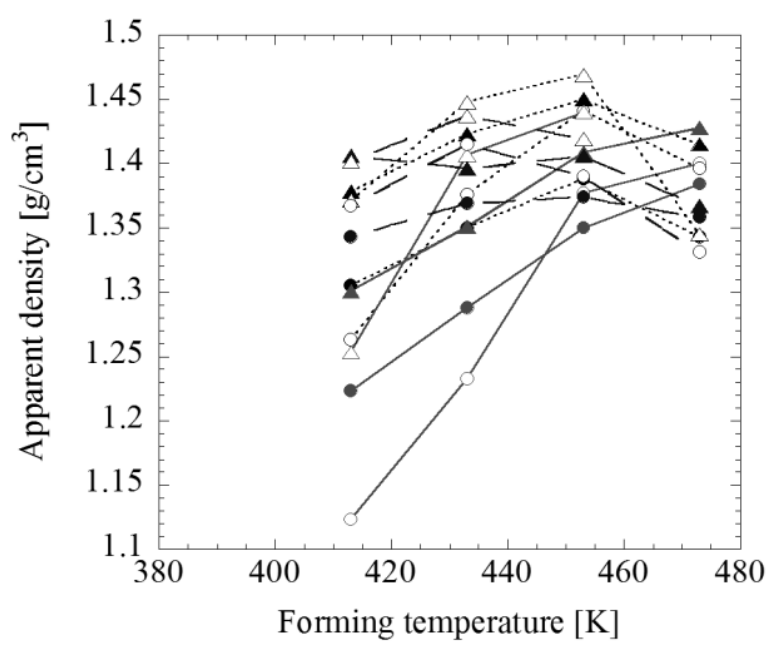

(a) Low initial moisture content: 5, 7, and 10wt $\%$

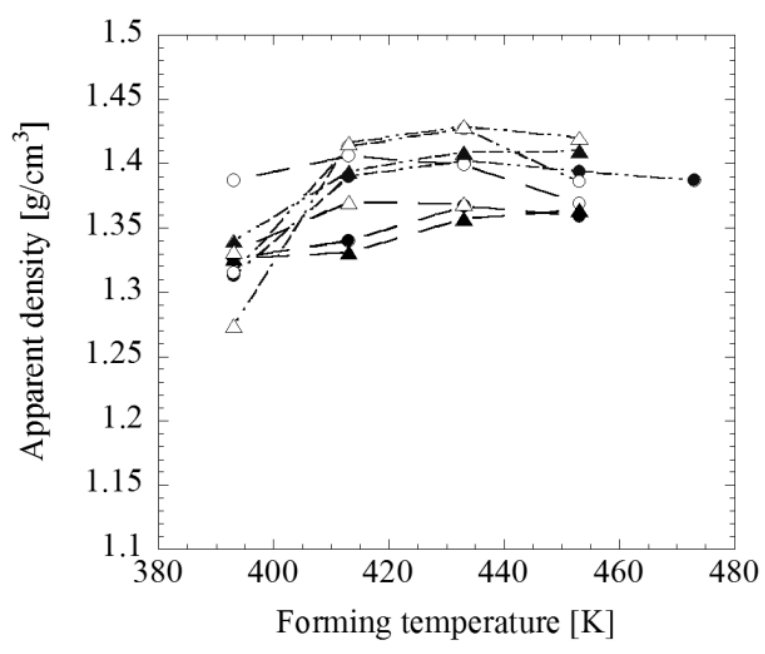

(b) High initial moisture content: 12 and $15 \mathrm{wt} \%$

Fig. 5 Apparent density of BIC from different forming conditions: Trunk of conifers $(\mathbf{O})$, Bark of conifers $(\bigcirc)$, Bagasse $(\Delta)$, Rice straw $(\triangle)$, Solid line: $5 \mathrm{wt} \%$, Dotted line: $7 \mathrm{wt} \%$, Chain line: $10 \mathrm{wt} \%$, Two-dot chain line: $12 \mathrm{wt} \%$, Broken line: $15 \mathrm{wt} \%$.

low temperature. It is suggested that hydrolysis progresses enough at $413 \mathrm{~K}$ because the apparent density of BIC samples at $413 \mathrm{~K}$ and high initial moisture content reaches the truth density. The apparent density of rice straw BIC at $453 \mathrm{~K}$ with $7 \mathrm{wt} \%$ initial moisture content is the highest at $1.47 \mathrm{~g} / \mathrm{cm}^{3}$. The apparent density of trunk BIC at $413 \mathrm{~K}$ with $5 \mathrm{wt} \%$ initial moisture content is the lowest at $1.12 \mathrm{~g} / \mathrm{cm}^{3}$.

\subsection{Compressive strength}

Fig. 6 shows the results of the compressive strength of BIC from each material of different forming conditions. At first, if we take note of which samples were BIC that has the highest compressive strength made from, we find that it is trunk BIC. It has the compressive strength of $183 \mathrm{MPa}$ at $453 \mathrm{~K}$ and $5 \mathrm{wt} \%$ initial moisture content. The maximum compressive strength of BIC from each material decreases successively in the following order: bagasse $(178 \mathrm{MPa})$, rice straw $(150 \mathrm{MPa})$, and bark (134 MPa). We will discuss the effect of moisture content and materials on the BIC compressive strength. The cellulose-rich trunk and bagasse show the followings finding for the forming temperature and the initial moisture content. For the low initial moisture content (5-10wt\%), the forming temperature increases the compressive strength and it reaches the maximum value at $453 \mathrm{~K}$. In addition, the difference between the maximum value and the minimum value of trunk and bagasse BIC is large (65 MPa). On the other hand, the compressive strength is constant for high initial moisture content (12-15wt\%) regardless of the forming temperature and the initial moisture content. As above, this is due to the hydrolysis reaction conditions of hemicellulose. Hemicellulose does not hydrolyze under the low initial moisture content and the low forming temperature, but hemicellulose hydrolyze enough under the high initial moisture content. The lignin-rich bark has the same trend as trunk and bagasse for the compressive strength for the low initial moisture content. However, the compressive strength of bark BIC is the maximum value at $433 \mathrm{~K}$ and $10 \mathrm{wt} \%$. We found that some water is necessary to form lignin-rich BIC. The compressive strength of hemicellulose-rich rice straw BIC has a little effect on the forming conditions. The difference between the maximum value and the minimum value of rice straw BIC is small (40 MPa, except at 473K). Rice straw BIC has the steadiest strength of range 110-150 MPa irrespective of the forming conditions. These results show that the relations between the compressive strength at room temperature and the forming conditions are decided by the percentage of components included in raw materials. In this study, for $15 \mathrm{wt} \%$ initial moisture content at 393K the compressive strength of BIC was achieved over $100 \mathrm{MPa}$. The compressive strength of each BIC formed at $473 \mathrm{~K}$ drops down. It is presumed that a function as the adhesive is not enough because a part of components (low molecule ingredients of hemicellulose and lignin) is pyrolyzed.

Fig. 7 shows the maximum compressive strength for each forming condition of each material. The maximum 
compressive strength is the highest compressive strength for each material of all conditions in this study. The maximum compressive strength increases with a high content of cellulose in the raw material. We find that the maximum compressive strength has a directly proportional relation to cellulose content. With increasing the initial moisture content, the maximum compressive strength decreases. A quadratic curve could approximate the maximum strength for hemicellulose content. The maximum value of the maximum strength is when the component ratio is approximately $25 \%$ of hemicellulose. The maximum strength at a component ratio approximately $30 \%$ is highest. The lowest initial moisture content tends to increase the maximum strength for each component. The structure of biomass is often compared to steel reinforced concrete. Cellulose and hemicellulose correspond to steel reinforced and concrete, respectively. Lignin works as an adhesive of cellulose and hemicellulose. In addition, the increase of cellulose content increases the compressive strength so that cellulose is stable material chemically. In contract, the compressive strength decreases when the percentage of hemicellulose content exceeds the specified amount because hemicellulose is an adhesion ingredient. Moreover, the initial moisture content affects the hydrolysis of hemicellulose and it is that the high moisture content is caused a loss of strength.

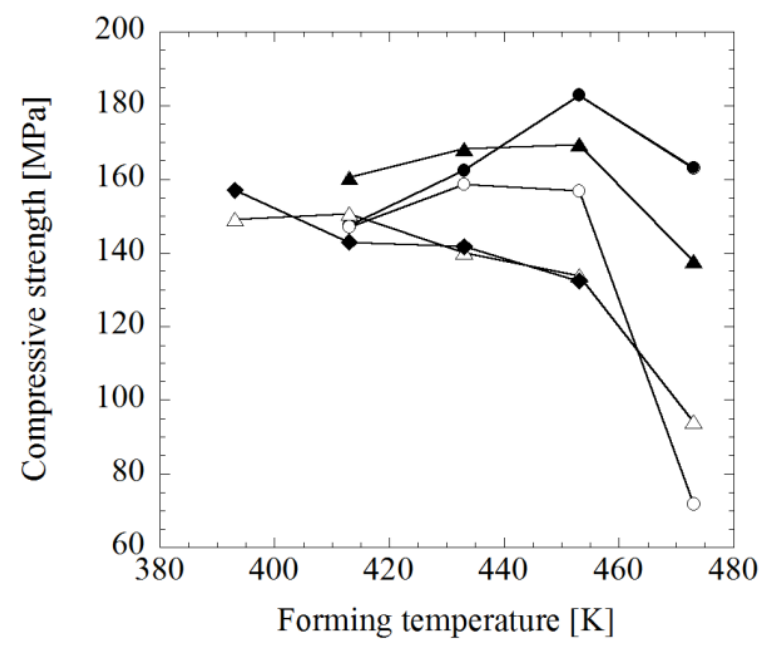

(a) Trunk of conifers

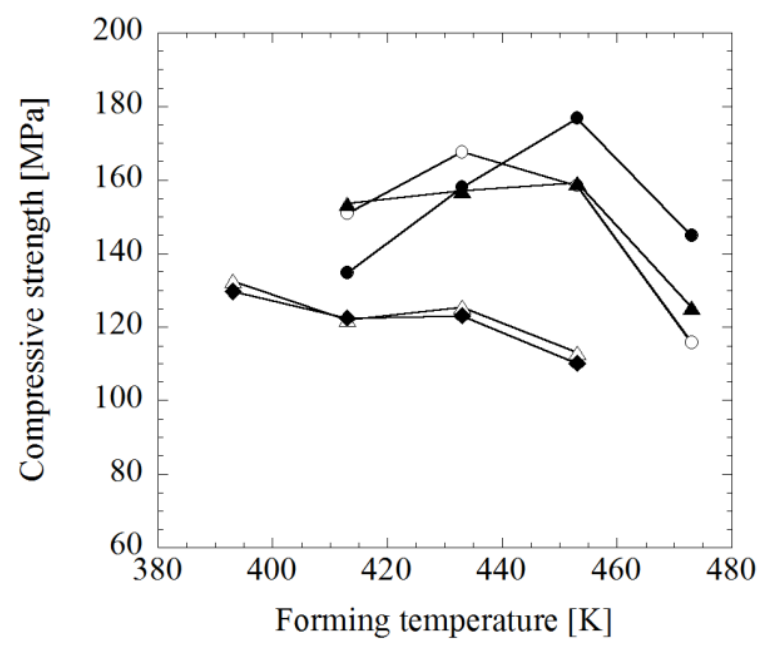

(c) Bagasse

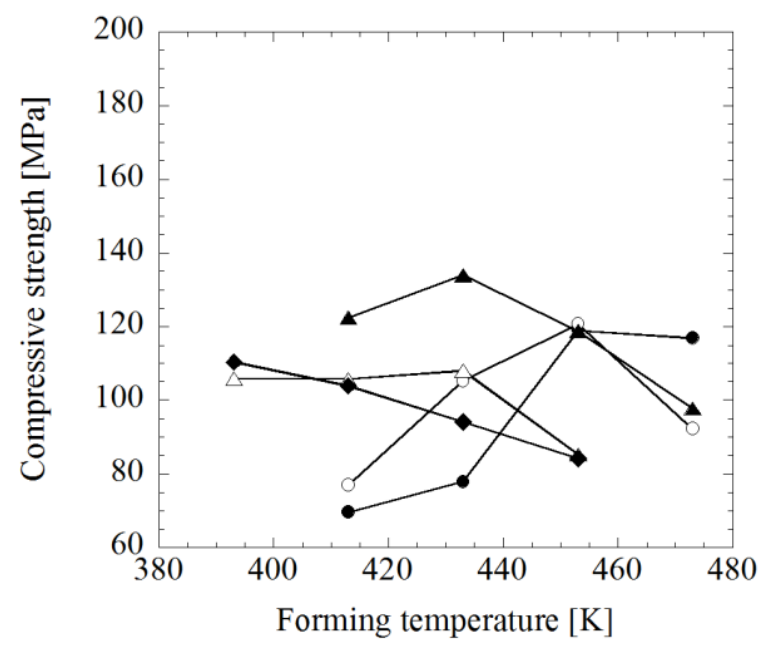

(b) Bark of conifers

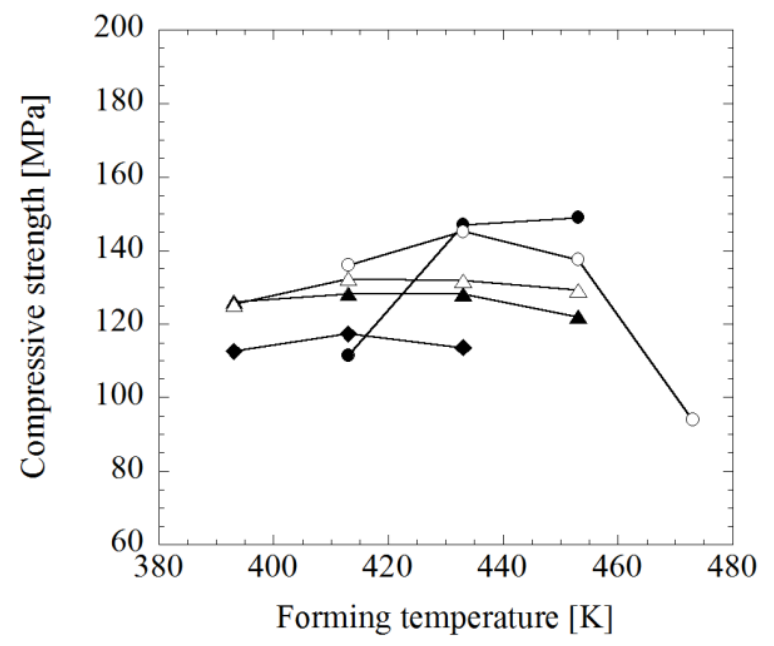

(d) Rice straw

Fig. 6 Maximum compressive strength of BIC from different forming conditions: Initial moisture content: $5 \mathrm{wt} \%$ ( ), $7 \mathrm{wt} \%(\bigcirc), 10 \mathrm{wt} \%(\mathbf{\Delta}), 12 \mathrm{wt} \%(\triangle), 15 \mathrm{wt} \%$

\section{Conclusions}




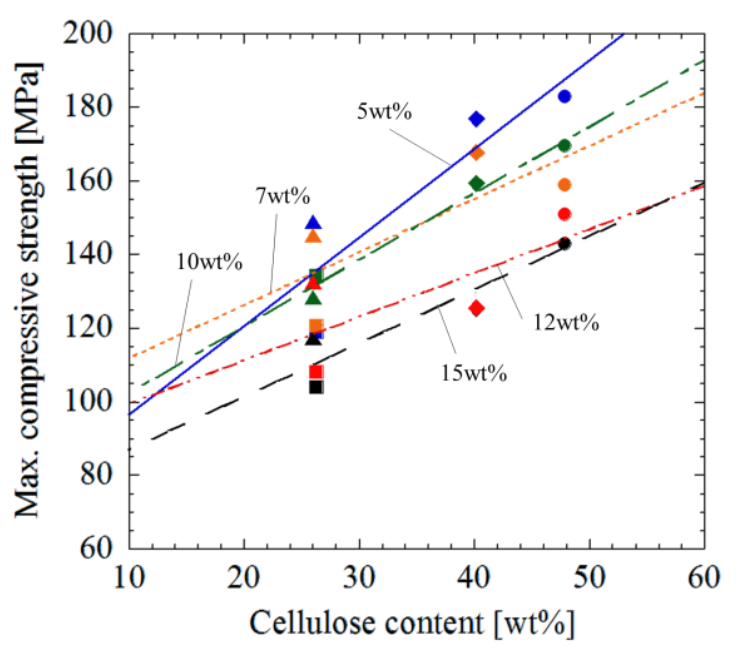

(a) Cellulose

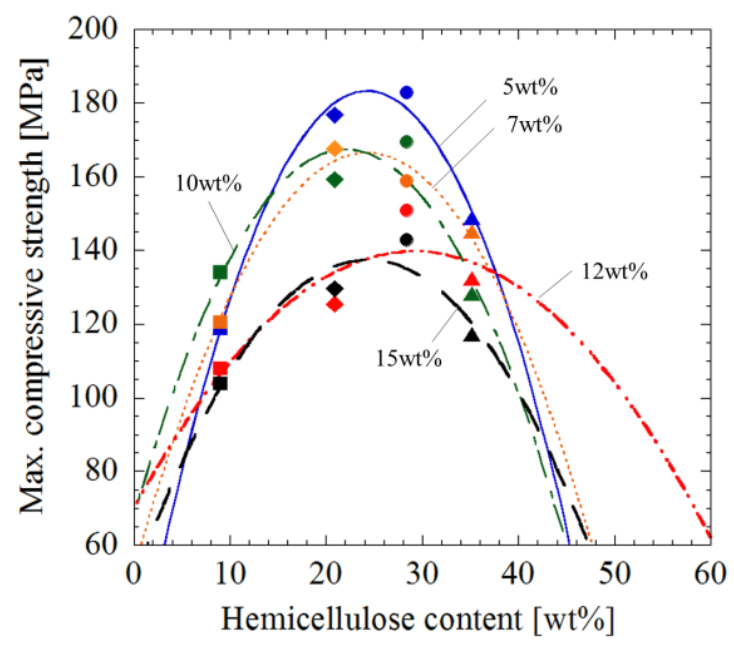

(b) Hemicellulose

Fig. 7 Maximum strength of each condition for composition content: Trunk of conifers ( $\mathbf{O})$, Bark of conifers ( $\boldsymbol{\square})$, Bagasse $(\diamond)$, Rice straw $(\boldsymbol{\Delta})$, Solid line (blue): $5 \mathrm{wt} \%$, Dotted line (orange): $7 \mathrm{wt} \%$, Chain line (green): $10 \mathrm{wt} \%$, Two-dot chain line (red): $12 \mathrm{wt} \%$, Broken line (black): $15 \mathrm{wt} \%$.

The following obtained for different components (cellulose, hemicelluose, and lignin) of four biomass (trunk from conifers trees, bark from conifers trees, bagasse, and rice straw) and the compressive strength of Biocoke.

1. To optimize the forming condition increases the apparent density of BIC. BIC with the initial moisture content higher than $10 \mathrm{wt} \%$ had a high apparent density $\left(1.33-1.45 \mathrm{~g} / \mathrm{cm}^{3}\right)$.

2. Trunk BIC has the highest compressive strength among BIC made from four biomass which was $183 \mathrm{MPa}$ at $453 \mathrm{~K}$ and $5 \mathrm{wt} \%$ initial moisture content. The maximum compressive strength of BIC decreases as follows: bagasse (178 $\mathrm{MPa})$, rice straw (150 $\mathrm{MPa}$ ) and bark (134 MPa).

3. As the initial moisture content increases, the forming temperature of the maximum compressive strength decreases. In this study, for $15 \mathrm{wt} \%$ initial moisture content at $393 \mathrm{~K}$ the compressive strength of BIC was achieved over $100 \mathrm{MPa}$.

4. The maximum compressive strength has a directly proportional relation to cellulose content in raw material. A quadratic curve could approximate the maximum strength for hemicellulose content.

\section{Acknowledgement}

The authors would particularly like to thank Dr. Kajimoto T. from Industrial Technology Center of Wakayama Prefecture for giving us the technical support.

This research is part of the "Effect of compressive strength of BIC on different structural components" project, applied by Dr. Mizuno S. from Kindai University, which was by "Faculty Assistance and Development Research Grant" from Kindai University and Private University Research Branding Project from The Ministry of education, culture, sports, science and technology, Japan.

\section{Reference}

Fuchihata, M., Ida, T. and Mizuno, S., BIC no Seikei Ondo no Chigai ga Nensyo Kyodo ni Oyobosu Eikyo, Reports of Kindai University, Research Institute of BIC, Vol.11 (2013), pp.17-23 (in Japanese).

Furuta, Y., Mokuzai no Rheology Kyodo to Netsuteki Tokusei, Rheology and Thermal Characteristics of Wood, Materials Science and Technology of Japan, Vol.42, No.3 (2005), pp.127-132 (in Japanese).

Goto, R., Namba, K., Ida, T. and Mizuno, S., Fundamental Study on Combustibility Promotion of BIC, Journal of Smart Processing, Vol.1, No.2 (2012), pp.71-78 (in Japanese).

Honjo, T., Biomass Solid Fuel, Journal of High Temperature Society, Vol.34 No.4 (2008), pp.146-152 (in Japanese).

Idei, T., Mokuzai no Kagaku-sosei, Jodai, S. and Sameshima, K. Eds, Mokuzai kagaku kouza 4. Kagaku, Kaiseisya Press, (1994), pp.15-32 (in Japanese).

Ishii, K., Murata, H., Kuwana, I., Mizuno, S., Morita, A. and Ida, T., Combustion Simulation and Quick-freeze 
Observation of a Cupola-furnace Process Using a BIC Fuel Based on Tea Scum, Journal of High Temperature Society, Vol.35, No.2 (2009), pp.91-96 (in Japanese).

Ito, H., Sakai, M., Nakahara, T., Ida, T. and Fujita, O., Studies on Solid Biomass Combustion-Combustion Characteristics of Highly Densified Biomass Briquette-, Journal of Smart Processing, Vol.1, No.2 (2012), pp.36-43 (in Japanese).

Mizuno, S., Ida, T. and Fuchihata, M., A Study of Physical Properties of High-Density Solid Biomass, BIC, with Unutilized Biomass, Journal of JSEM, Vol.11 (2011), pp.19-24.

Mizuno, S., Ida, T., Fuchihata, M., Namba, K., Kakosaka, A. and Fujita, O., Formation Characteristics of High-density and High-hardness New Briquette Based on Herby Biomass, Journal of the Japan Institute of Energy, Vol.91, No.1 (2012), pp.41-47 (in Japanese).

Mizuno, S., Ida, T., Fuchihata, M., Sanchez Jr, E. and Yoshikuni, K., Formation Characteristics of BIC Produced From Waste Agricultural Biomass, Proceedings of InterPACK/ICNMM2015, (2015).

Rabemanolontsoa, H. and Saka, S., Quantitative method applicable for various biomass species to determine their chemical composition determine their chemical composition, BIOMASS \& BIOENERGY, Vol.35, No.11 (2011), pp.4630-4635.

The Japan Wood Research Society Ed., Mokuzai Kagaku Jikken Syo II Kagakuhenn, Tyugaisangyou Chousakai, (1985), pp.150-155 (in Japanese).

The Japan Wood Research Society Ed., Mokushitsu Kagaku Jikken Manual, Buneido-shuppan, (2000), pp.94-97 (in Japanese). 